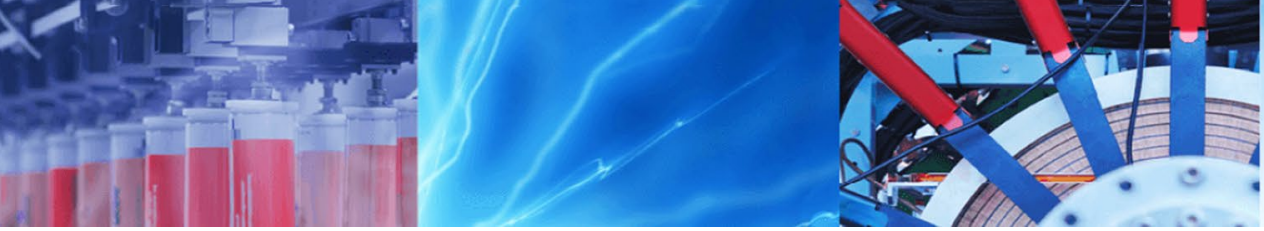

Research Article

\title{
The brown algae Cystoseira Baccata extract as a friendly corrosion inhibitor on carbon steel in acidic media
}

\author{
T. Benabbouha ${ }^{1}$ (1) R. Nmila ${ }^{2} \cdot$ M. Siniti ${ }^{1} \cdot$ K. Chefira ${ }^{3} \cdot$ H. El Attari ${ }^{3} \cdot$ H. Rchid ${ }^{2}$
}

Received: 18 January 2020 / Accepted: 11 March 2020 / Published online: 16 March 2020

(c) Springer Nature Switzerland AG 2020

\begin{abstract}
The inhibition properties of the isopropanol extract of brown seaweed Cystoseira baccata (CBE), against corrosion of carbon steel in $\mathrm{HCl} 1 \mathrm{M}$ medium, was evaluated using the weight-loss method and electrochemical measurements. It was shown that the extract exhibit excellent performance as inhibitors and the inhibition efficiency increased with the concentration. The maximal value of inhibition efficiency is $86.5 \%$ obtained by the Tafel method at $700 \mathrm{mg} / \mathrm{l}$ at $298 \mathrm{~K}$. The polarization curves indicate that the CBE acts as a mixed-type inhibitor. The results obtained by electrochemical impedance spectroscopy shows that the inhibitory action of this extract is based on the increase in the charge transfer resistance and the decrease in the double layer capacity. The temperature influence studied in the temperature range 298-328 K by weight-loss method shows that the inhibition efficiency decreases with increasing temperature for all concentrations of CBE. The adsorption and activation parameters allow us to suggest the physical adsorption of this inhibitor on the metal. The adsorption of the extract on the carbon steel follows Langmuir adsorption isotherm.
\end{abstract}

Keywords Corrosion inhibitor $\cdot$ Carbon steel $\cdot$ Acid media $\cdot$ Seaweed $\cdot$ Cystoseira baccata $\cdot$ Extract

\section{Introduction}

Corrosion inhibitors are chemical compounds added at low concentrations in a corrosive environment to slow down or stop the corrosion process of metal [1,2]. Most of these substances are organic compounds that mainly contain heteroatoms such as oxygen, sulphur and nitrogen and are capable of adsorbing multiple bonds on the metal surface $[3,4]$. Although synthetic inhibitors have shown good anticorrosive activity, most of them are highly toxic to humans and the environment [5]. The toxicity can be manifested either during the synthesis of the compound or during its applications. Current research is increasingly focused on the use of inhibitors called green inhibitors. The non-toxic and biodegradable nature of natural products has led to their use as ecological inhibitors [6-9].
Since 1930, plant and algae extract has been used as a corrosion inhibitor. Studies on natural products extract as a corrosion inhibitor has become more extensive [10-17]. Cystoseira baccata brown algae from the Sargassaceae family considered as a natural source of several active compounds. It is already known as such antibacterial, antifouling, antioxidant, Antileishmanial activities [18-21].

In the continuation of our study on the corrosion inhibition potential of marine algae. We have evaluated the corrosion inhibition power of the isopropanol extract of Cystoseira baccata (CBE) on carbon steel in $1 \mathrm{M} \mathrm{HCl}$, using three methods of weight loss, potentiodynamic polarization and (EIS), thus understanding the mechanism of inhibition of this extract.

T. Benabbouha, bentariq@gmail.com | 'Equipe de Thermodynamique, Surfaces et Catalyse, Faculté des Sciences, Université Chouaib Doukkali, 24000 El-Jadida, Morocco. ${ }^{2}$ Equipe de biotechnologie et valorisation des ressources végétales, Faculté des Sciences, Université Chouaib Doukkali, 24000 El-Jadida, Morocco. ${ }^{3}$ Laboratoire de Chimie de Coordination et d'Analytique, Faculté des Sciences, Université Chouaib Doukkali, 24000 El-Jadida, Morocco. 


\section{Experimental details}

\subsection{Preparation of Cystoseira baccata extract}

Cystoseira baccata (Sargassaceae) harvested at El-Jadida beach (Atlantic sea, Morocco), was extensively washed with distilled water and dried in the shade at room temperature. The seaweed powder was delipidated by hexane for $8 \mathrm{~h}$ after the extract was prepared by soxhlet extraction of powder in isopropanol $70 \%$ for $8 \mathrm{~h}$. After evaporation and freeze-drying, the extract was kept in a desiccator. The $C B E$ was dissolved in $1 \mathrm{M} \mathrm{HCl}$, appropriately diluted to get solutions of desired concentrations.

\subsection{Specimen preparation}

The carbon steel (CS) specimens with dimensions of $40 \mathrm{~mm} \times 10 \mathrm{~mm} \times 1 \mathrm{~mm}$ in size, with a mass composition of C $=0.38 \%, \mathrm{Si}=0.21 \%, P=0.09 \%, \mathrm{~S}=0.05 \%, \mathrm{Mn}=0.05 \%$, $\mathrm{Al}=0.01 \%$ and the remainder iron. The pretreatment of the surfaces of the specimens was carried out by polishing with 500, 1000, 1500 and 2000 grit emery paper, followed by washing with double-distilled water. The surface was finally degreased with ethanol and acetone and then dried at room temperature.

\subsection{Weight loss measurement}

For the determination of the corrosion rate of carbon steel (CS), gravimetric tests were performed in a thermostatically controlled water bath with a temperature regulator, in the temperature of the range (298-328 K). The CS samples were immersed in $30 \mathrm{ml}$ of $1 \mathrm{M} \mathrm{HCl}$ with different extract concentrations ranging from 0 to $700 \mathrm{mg} / \mathrm{l}$ for $6 \mathrm{~h}$ of immersion. After the end of the time period prescribed for the test, the sample was taken out, washed thoroughly with distilled water, dried, and accurately weighed using a digital balance (accuracy: $\pm 0.1 \mathrm{mg}$ ). Each measurement was repeated three times, and the average values were recorded.

The corrosion rate $(W)$, inhibition efficiency (IE\%), and surface coverage $(\Theta)$, were calculated according to the following equations: [22]:

$w(m m p y)=87600 . \Delta m / d . S . t$

$I E \%=100 * \theta=100 *\left(w_{0}-w\right) / w_{0}$

where $\Delta m(\mathrm{~g})$ is the weight loss, $d$ is the density of coupon in $\left(\mathrm{g} \mathrm{cm}^{-3}\right), S$ is the area of the specimen $\left(\mathrm{cm}^{2}\right)$, and $t$ is the immersion time in hours, $w_{0}$ and $w$ are the corrosion rates (mmpy) of the sample in the absence and presence of the inhibitor, respectively.

\subsection{Electrochemical measurements}

Electrochemical testing is the method most commonly used for research into corrosion. It can analyze the corrosion of mild steel under transient conditions and can also describe the whole corrosion process of mild steel in a corrosive medium.

Electrochemical measurements were carried out in three-electrode Pyrex glass cell. The CS as a working electrode (WE) in the square form with the geometric area of $1 \mathrm{~cm}^{2}$ embedded in PVC carrier using epoxy resin. So that the flat surface was the only surface in the electrode, a platinum counter electrode (CE) and a saturated calomel electrode (SCE) was used as the reference. The equipment used is EC-Lab SP 200 Research Grad model potentiostat/ galvanostat/FRA, and the experimental data analyzed by EC-Lab software. Open-circuit potential $\left(E_{o c p}\right)$ was obtained by immersing the working electrode in the test solution for $30 \mathrm{~min}$. The impedance measurements were performed in the frequency range from $100 \mathrm{kHz}$ to $10 \mathrm{mHz}$, with 8 points per decade, by applying $10 \mathrm{mV}$ alternating current (AC) voltage peak-to-peak. The potentiodynamic curves were realized polarization from $-1 \mathrm{~V}$ to $1 \mathrm{~V}$ relative to the $E_{\text {ocp }}$ with a scan rate of $1 \mathrm{mV} / \mathrm{s}$ in the potential.

\subsection{Fourier-transform infrared spectroscopy (FTIR)}

FTIR spectra of Cystoseira baccata extract and the scraped product from CS after $6 \mathrm{~h}$ of immersion in $1 \mathrm{M} \mathrm{HCl}$ containing $700 \mathrm{mg} / \mathrm{l}$ of CBE were recorded on a SHIMADZU FT-IR $8400 \mathrm{~S}$ spectrometer with a Smart iTR Attachment and diamond attenuated Total Reflectance (ATR) crystal in range $500-4000 \mathrm{~cm}^{-1}$.

\section{Results and discussion}

\subsection{Potentiodynamic Polarization}

Figure 1 shows polarization curves for steel in $1 \mathrm{M} \mathrm{HCl}$ media, without and with the addition of various concentrations of $C B E$. The values of different polarization parameters such as corrosion current density $\left(I_{\text {corr }}\right)$, corrosion potential $\left(E_{\text {corr }}\right)$, Tafel coefficients cathodic $\left(\beta_{c}\right)$ and anodic $\left(\beta_{a}\right)$ and inhibition efficiency IE\% were listed in Table 1.

The inhibition efficiency of IE\% was calculated as follows [23]: 


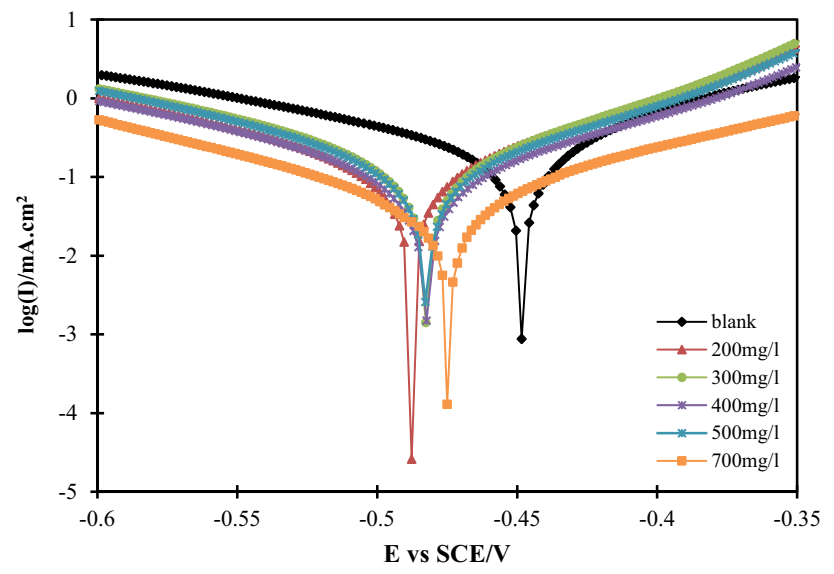

Fig. 1 Potentiodynamic polarization plots for steel in $1 \mathrm{M} \mathrm{HCl}$ media, without and with the addition of various concentrations of $C B E$

Table 1 Potentiodynamic polarization data for carbon steel in $1 \mathrm{M}$ $\mathrm{HCl}$ in the absence and presence of various concentrations of $C B E$

\begin{tabular}{llllll}
\hline $\begin{array}{l}\text { Concentration } \\
(\mathrm{mg} / \mathrm{l})\end{array}$ & $\begin{array}{l}\mathrm{E}_{\text {corr }} \\
(\mathrm{mV} / \mathrm{SCE})\end{array}$ & $\begin{array}{l}\mathrm{b}_{\mathrm{a}} \\
(\mathrm{mV} / \mathrm{dec})\end{array}$ & $\begin{array}{l}\mathrm{b}_{\mathrm{c}} \\
(\mathrm{mV} / \mathrm{dec})\end{array}$ & $\begin{array}{l}\mathrm{I}_{\text {corr }} \\
\left(\mu \mathrm{A} / \mathrm{cm}^{2}\right)\end{array}$ & $\begin{array}{l}\mathrm{IE} \\
(\%)\end{array}$ \\
\hline Blank & -449.3 & 133 & 189.1 & 320.8 & - \\
200 & -487.7 & 92.8 & 108.7 & 107.2 & 66.5 \\
300 & -481.9 & 91.5 & 96.4 & 100.8 & 68.5 \\
400 & -481.5 & 98.2 & 108.3 & 87.7 & 72.6 \\
500 & -481 & 107.5 & 96.6 & 83.8 & 73.8 \\
700 & -475 & 110.4 & 114.6 & 44.2 & 86.2 \\
\hline
\end{tabular}

$I E \%=\frac{\left(I_{\text {corr }}^{\circ}-I_{\text {corr }}\right)}{l_{\text {corr }}^{\circ}} \times 100$

$I_{\text {corr }}^{\circ}$ and $I_{\text {corr }}$ are the values of corrosion current density in the absence and presence of inhibitors, respectively.

From Fig. 1, it can be observed that the cathode curves are a linear part, in the form of Tafel lines, indicating that the hydrogen reduction reaction on the steel surface is carried out according to a precise activation mechanism [15].

Table 1 shows that the values of the corrosion current density $I_{\text {corr }}$ decrease with the addition of different concentrations of $C B E$. Also, the corrosion potential $\left(E_{\text {corr }}\right)$ moves slightly $(-39 \mathrm{mV})$ with the concentration of extract towards the less noble values, and according to [24], if the displacement of the potential exceeds $\pm 85 \mathrm{mV}$, the inhibitor acts as a cathodic or anodic type. If the displacement of the $E_{\text {corr }}$ values does not exceed $\pm 85 \mathrm{mV}$, the inhibitor can be considered as a mixed type. Additionally, this extract causes no remarkable change in the anodic and cathodic Tafel slopes $\left(\beta_{a}, \beta_{c}\right)$. And both the cathodic and anodic reactions were affected by a reduction of the anodic dissolution of steel and also retarded the cathodic hydrogen evolution reaction. These results suggest that the $C$. baccata extract functioned as a mixed type inhibitor $[25,26]$.

\subsection{Electrochemical impedance spectroscopy}

The Cystoseira baccata extract Nyquist curves on CS in hydrochloric acid medium $1 \mathrm{M}$ shown in Fig. 2, reveal that the diameter of the semicircles of the Nyquist diagram increases with increasing extract concentration. Those semi-circles are not perfect; this result attributed to the frequency dispersion, due to the heterogeneity of the surface of the electrode. The impedance spectra have a single capacitive loop indicating that the corrosion of the steel is mainly controlled by a charge transfer process on an inhomogeneous surface electrode [27]. Indeed, only one time constant is detected on the Bode diagram presented in Fig. 3. The equivalent circuit used is well described in [28] and shown in Fig. 4.

The electrochemical impedance parameters, the charge transfer resistance $R_{c t}$, the solution resistance $R_{s^{\prime}}$ the double layer capacitance $C_{d l}$, slope $(S)$, phase angle $(\Phi)$, and inhibition efficiency IE\% are given in Table 2.

The inhibition efficiency IE\% is calculated from the following formula [29]:

$\mid E \%=\left(\frac{R_{c t}-R_{c t}^{\circ}}{R_{c t}}\right) \times 100$

with $R_{c t}^{\circ}$ and $R_{c t}$ are the charge transfer resistance without and with inhibitor, respectively.

The impedance of the CPE represented by the following expression [30]:

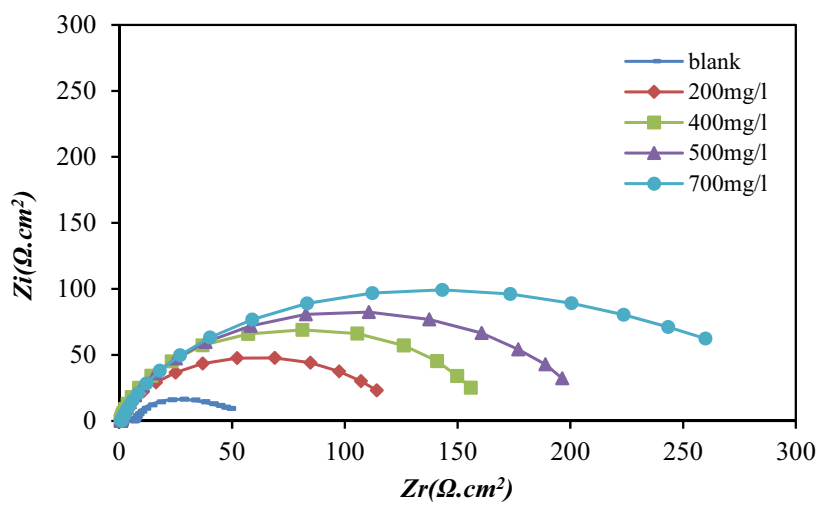

Fig. 2 Nyquist plots for $\mathrm{CS}$ in $1 \mathrm{M} \mathrm{HCl}$ without and with various concentrations of $C B E$ 

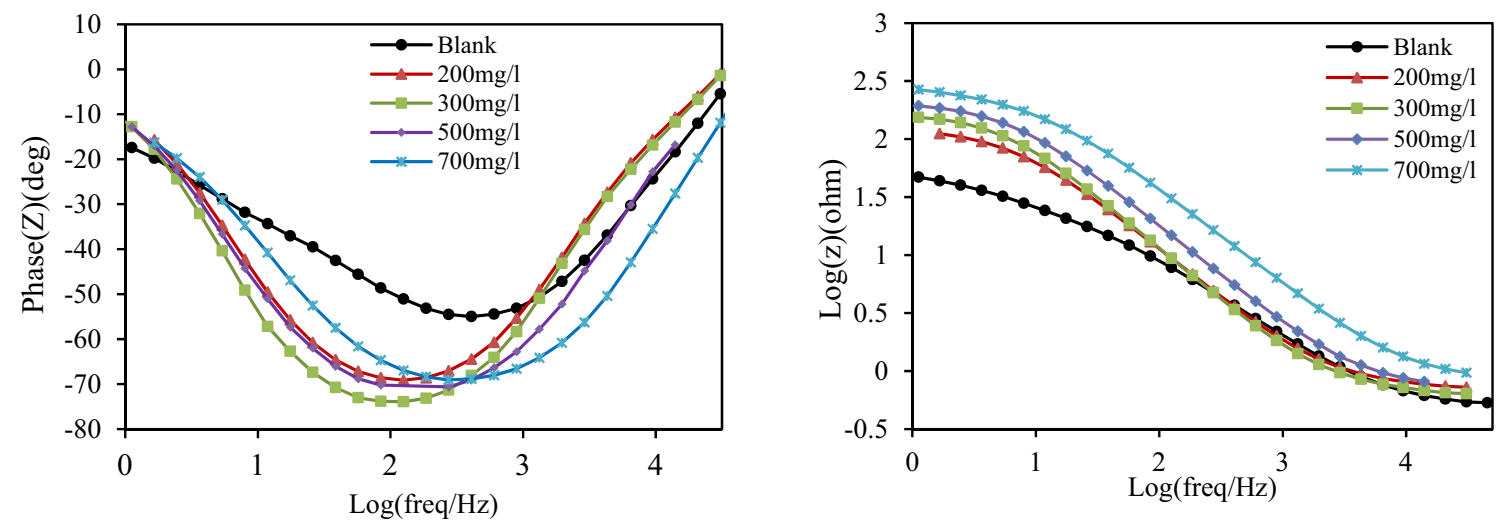

Fig. 3 Bode diagram for $\mathrm{CS}$ in $1 \mathrm{M} \mathrm{HCl}$ with different concentrations of $C B E$

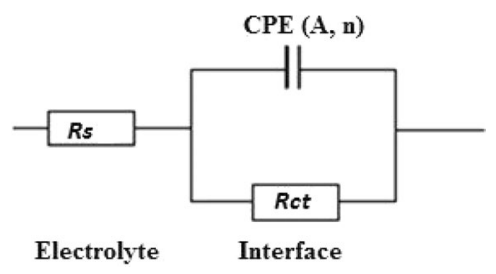

Fig. 4 Equivalent circuit model used

$$
Z_{\text {CPE }}=A^{-1}(i \omega)^{-n}
$$

where $A$ is the amplitude comparable to a capacitance, $i^{2}=-1, \omega$ the angular frequency and $n$ the phase shift $(-1<n<1)$ when $n=0$ the CPE represents pure resistor, if $n=1$, the CPE is reduced to a pure capacitor (C), and if $n=-1$ the CPE represents inductor and When $n=0.5$, it is the Warburg impedance (W) [31].

The double-layer capacitance $\left(C_{d l}\right)$ calculated from the constant phase element (CPE) is presented by [32]:

$C_{d l}=\left(A * R_{c t}^{1-n}\right)^{1 / n}$

It is quite clear from Table 2 that, the $\mathrm{R}_{\mathrm{ct}}$ increase with the increase in inhibitor dosage, Therefore, the $C_{d l}$ and $A$ decrease in double-layer capacitance would signify the increase in the thickness of the capacitive surface layer which is an indication of gradual replacement of surface water molecules with inhibitor adsorption.

The $C_{d l}$ connected with the organic deposition thickness by the Helmotz relation (7) [33]:

$C_{d l}=\frac{\varepsilon \cdot \varepsilon_{0}}{d} S$

where $d$ is the thickness of the protective layer, $\varepsilon$ dielectric constant of the medium, $\varepsilon_{0}$ the vacuum permittivity and $S$ is the effective surface area of the electrode.

The least value of $C_{d l}$ and highest inhibition efficiency were obtained with $700 \mathrm{mg} \mathrm{I}^{-1}$ inhibitor dosage indicate the optimum surface coverage. At the optimum inhibitor concentration, the obvious effect of the hydrophobic backbone of the inhibitor can be elucidated by the increase in cohesive energy of absorbed mono-layer on the CS surface [34]. Nevertheless, an overall inhibition effect was remained intact may be due to the compaction of mono-layer upon achieving CBE of inhibitor which is evident with an increase in $R_{c t}$ and capacitance of film.

The phase shift values $n$ increase with the addition of the seaweed extract $(0.8401-0.9007)$ relative to the uninhibited solution (0.818), which indicates, according to Popova et al. [35], the decrease in the heterogeneity of the steel surface with the adsorption of inhibiting molecules. But they did not vary significantly, confirming that the dissolution mechanism of the steel in the absence and
Table 2 Electrochemical impedance parameters and inhibition efficiency of CS in $1 \mathrm{M} \mathrm{HCl}$ in the absence and presence of different concentrations of CBE

\begin{tabular}{|c|c|c|c|c|c|c|c|c|}
\hline $\begin{array}{l}\text { Concentration } \\
(\mathrm{mg} / \mathrm{l})\end{array}$ & $\mathrm{R}_{\mathrm{s}}$ & $A$ & $\mathrm{n}$ & $C_{d l}$ & $\mathrm{R}_{\mathrm{ct}}$ & $S$ & $-\Phi$ & IE\% \\
\hline Blank & 5.404 & 0.714 & 0.818 & 325.4 & 44.81 & -0.564 & 32.17 & - \\
\hline 200 & 0.724 & 0.333 & 0.8657 & 202.6 & 120.4 & -0.805 & 48.16 & 62.7 \\
\hline 300 & 0.65 & 0.262 & 0.9007 & 185.3 & 163.4 & -0.868 & 56.55 & 72.5 \\
\hline 500 & 0.719 & 0.207 & 0.8683 & 128.2 & 205 & -0.828 & 54.63 & 78.1 \\
\hline 700 & 0.873 & 0.12 & 0.8401 & 62.48 & 265.9 & -0.796 & 47.22 & 83.1 \\
\hline
\end{tabular}


presence of the extract is controlled by a charge transfer process [36].

Always with Table 2, it is clear that the slope $S$ of the linear part of the bode plots (log (f) vs. $\log (|Z|))$ decreases with the addition of $C B E$ concentration and that the values of the phase angle $(\Phi)$ in the presence of the extract higher than that of the blank. Generally, for an ideal capacitor, it is necessary that $S$ of -1 and a phase shift $(-\Phi)$ of $90^{\circ}[37$, 38]. From these results, it is deduced that the system tends to behave as a pure capacity.

\subsection{Effect of temperature}

Temperature is a critical factor in corrosion inhibitor evaluation studies. The effect of temperature makes it possible to determine the nature of adsorption of the inhibitor on the surface of the metal. Figure 5 shows the effect of temperature on the inhibition efficiency of CS in acid media, using the weight-loss method at various concentrations of CBE in the temperature range (298-328 K) during $6 \mathrm{~h}$ of immersion. Table 3 presents the values of corrosion rate and inhibition efficiency (IE\%) for CS in $1 \mathrm{M} \mathrm{HCl}$ in the absence and presence of a different concentration of the inhibitor. Figure 5 and Table 4 show an increase in

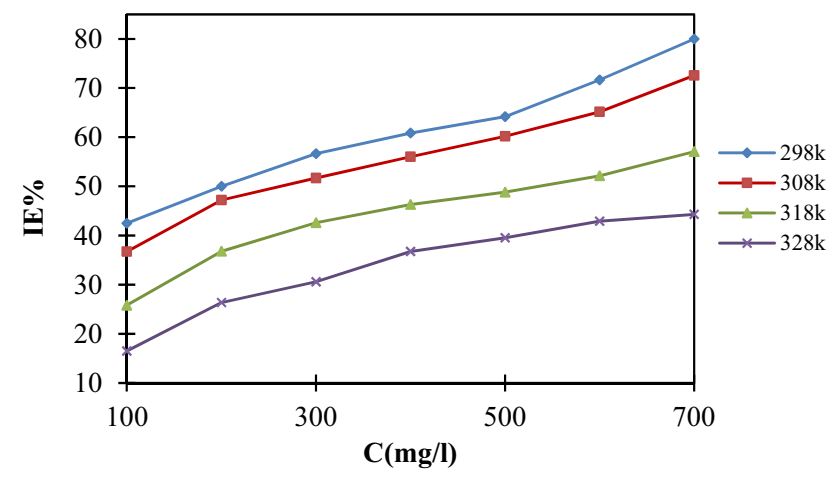

Fig. 5 Effect of temperature on IE\% for CS with different concentrations of C. baccata extract in $1 \mathrm{M} \mathrm{HCl}$
Table 4 Adsorption parameters of CBE on the steel surface at different temperatures

\begin{tabular}{|c|c|c|c|c|c|}
\hline & $\begin{array}{l}\text { Temperature } \\
\text { (K) }\end{array}$ & $\mathrm{R}^{2}$ & $\mathrm{~K}_{\mathrm{ads}}$ & $\begin{array}{l}\text { Constant } \\
\text { of iso- } \\
\text { therm }\end{array}$ & $\Delta \mathrm{G}_{\mathrm{ads}}$ \\
\hline \multirow[t]{4}{*}{ Langmuir } & 298 & 0.9631 & 5.5096 & $\begin{array}{l}\text { slope } \\
1.0869\end{array}$ & -21.34 \\
\hline & 308 & 0.9746 & 5.0505 & 1.1860 & -21.83 \\
\hline & 318 & 0.8661 & 1.1394 & 1.1623 & -18.60 \\
\hline & 328 & 0.9114 & 0.6564 & 1.0212 & -17.68 \\
\hline \multirow[t]{4}{*}{ Temkin } & 298 & 0.9186 & 2.0871 & $\begin{array}{l}a \\
-0.4593\end{array}$ & -18.93 \\
\hline & 308 & 0.9545 & 2.0263 & -0.4772 & -19.49 \\
\hline & 318 & 0.9904 & 1.8229 & -0.4952 & -19.85 \\
\hline & 328 & 0.9947 & 1.6386 & -0.4973 & -20.18 \\
\hline \multirow[t]{4}{*}{ Freundlich } & 298 & 0.964 & 0.8321 & $\begin{array}{l}f \\
0.30\end{array}$ & -16.65 \\
\hline & 308 & 0.9837 & 0.7762 & 0.32 & -16.48 \\
\hline & 318 & 0.9844 & 0.6529 & 0.38 & -16.05 \\
\hline & 328 & 0.984 & 0.5596 & 0.50 & -15.67 \\
\hline
\end{tabular}

corrosion rates and a decrease in the values of inhibition efficiency with increasing temperature for the different $C B E$ concentrations. The rise in temperature adversely affects the corrosion inhibiting action of $C B E$; this can be explained by the breakdown of the physical interactions between the molecules of the extract and the metal surface. This type of interaction is usually temperature sensitive and also is easily removed from the surface $[39,40]$.

\subsection{Adsorption isotherms and thermodynamic parameters}

The adsorption isotherm is a characteristic for studying solid/liquid equilibriums. It is a curve linking the quantity of adsorbate adsorbed by material, as a function of the equilibrium pressure (or concentration) of the adsorbate at a constant temperature. In our case, the relationship
Table 3 Influence of temperature on the corrosion parameters for CS in the absence and presence of a various concentrations of $\mathrm{CBE}$ in the temperature range (298-328 K) during $6 \mathrm{~h}$

\begin{tabular}{|c|c|c|c|c|c|c|c|c|}
\hline \multirow{2}{*}{$\begin{array}{l}\text { Concentration } \\
(\mathrm{mg} / \mathrm{l})\end{array}$} & \multicolumn{2}{|l|}{$298 \mathrm{~K}$} & \multicolumn{2}{|l|}{$308 \mathrm{~K}$} & \multicolumn{2}{|l|}{$318 \mathrm{~K}$} & \multicolumn{2}{|l|}{$328 \mathrm{~K}$} \\
\hline & $\begin{array}{l}\text { W } \\
\text { (mmpy) }\end{array}$ & $\begin{array}{l}\mathrm{IE} \\
(\%)\end{array}$ & $\begin{array}{l}\text { W } \\
\text { (mmpy) }\end{array}$ & $\begin{array}{l}\mathrm{IE} \\
(\%)\end{array}$ & $\begin{array}{l}\text { W } \\
\text { (mmpy) }\end{array}$ & $\begin{array}{l}\mathrm{IE} \\
(\%)\end{array}$ & $\begin{array}{l}\text { W } \\
\text { (mmpy) }\end{array}$ & $\begin{array}{l}\text { IE } \\
(\%)\end{array}$ \\
\hline Blank & 2.75 & - & 7.15 & - & 16.52 & - & 27.43 & - \\
\hline 100 & 1.57 & 42.8 & 4.23 & 40.80 & 12.53 & 24.14 & 22.90 & 16.53 \\
\hline 200 & 1.37 & 50 & 3.77 & 47.19 & 10.44 & 36.81 & 20.19 & 26.40 \\
\hline 300 & 1.19 & 56.8 & 3.45 & 51.71 & 9.48 & 42.61 & 18.94 & 30.95 \\
\hline 400 & 1.07 & 61.2 & 3.03 & 57.63 & 8.64 & 47.67 & 17.68 & 35.54 \\
\hline 500 & 0.98 & 64.2 & 2.84 & 60.28 & 8.45 & 48.81 & 16.58 & 39.56 \\
\hline 600 & 0.77 & 71.96 & 2.48 & 65.26 & 7.90 & 52.19 & 15.65 & 42.93 \\
\hline 700 & 0.55 & 80 & 1.96 & 72.58 & 7.08 & 57.11 & 15.28 & 44.31 \\
\hline
\end{tabular}


between the surface coverage $\theta$ and the level $C_{i n h}$ of the inhibitor. Several theoretical models have been tested to describe the behaviour of inhibitors in the corrosion process, such as Langmuir, Temkin, and Freundlich [41-43]:

Langmuir : $\quad \frac{C_{i n h}}{\theta}=\frac{1}{K_{\text {ads }}}+C_{\text {inh }}$

Temkin : $\quad \exp (-2 a \theta)=K C_{i n h}$

Freundlich : $\quad \operatorname{Ln} \theta=\operatorname{Ln} K_{a d s}+f . \operatorname{LnC} C_{i n h}$

where $C_{i n h}$ is the concentration of the inhibitor, $\theta$ is the surface coverage, and $K_{\text {ads }}$ is the adsorptive equilibrium constant, $a$ is interaction constant between adsorbed particles and $f$ is Freundlich isotherm interaction constant.

Figure 6 shows the graphical representations of the relationship between $\theta$ and $C_{i n h}$ at different temperatures for different models of isotherms. Table 4 presents the values of the correlation coefficient $\left(R^{2}\right)$, slopes, intercepts, $K_{\text {ads }}$, $a, f$ and those the free adsorption standard energy $\Delta G_{a d s}^{\circ}$ he $K_{\text {ads }}$ values obtained made it possible to evaluate the $\Delta G_{\text {ads }}^{\circ}$ (Table 4), by using the following equation [44]:

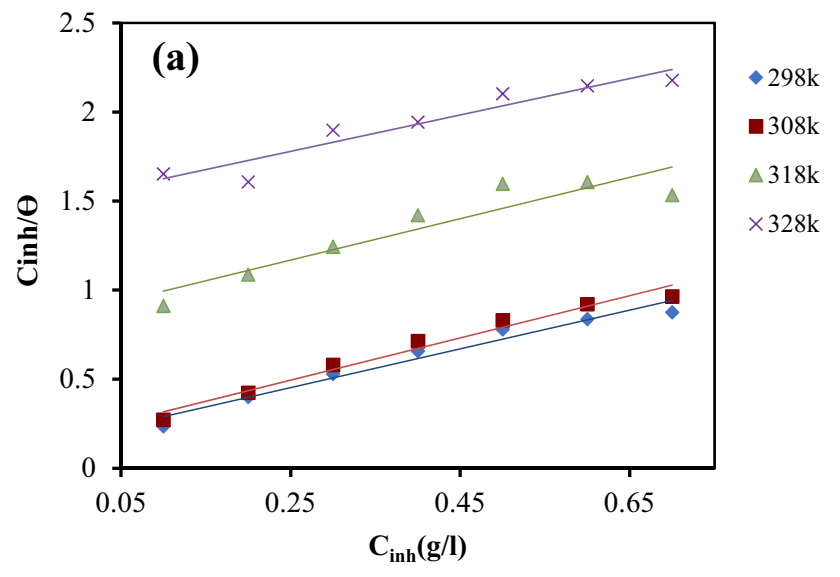

$\Delta G_{a d s}^{\circ}=-R T \operatorname{Ln}\left(C_{\mathrm{H}_{2} \mathrm{O}} \dot{K}_{a d s}\right)$

where $C_{\mathrm{H}_{2} \mathrm{O}}=10^{3} \mathrm{~g} / \mathrm{l} . R$ is the universal gas constant, $T$ is the absolute temperature.

The values of the correlation coefficient $R^{2}$ for the three isotherms are close to 1 . The values of the Freundlich isothermal coefficient $f$, which describes the ease with which active species adsorb to the metal surface, which indicates that adsorption of the molecules is feasible $(0<f<1)$ [45], but they disagree with an ideal value of $n=0.6$ [46]. The means that the process of adsorption of this extract does not follow this isotherm. Negative signs of Temkin isotherm interaction parameters $a$ indicate molecular repulsion in the adsorbed layer of the adsorbate, demonstrating that Temkin isotherm is not suitable for our inhibitor [47]. For Langmuir, isotherm plots have a linear behaviour with equal slopes roughly unity. This suggests that the adsorption of $C B E$ on the steel surface obeyed to the Langmuir's adsorption isotherm.

Generally, negative values of $\Delta G_{a d s}^{\circ}$ indicate spontaneous adsorption of CBE and values less than or equal to $-20 \mathrm{~kJ} . \mathrm{mol}^{-1}$ are related to physical interactions between charged molecules and metallic charges. In contrast,

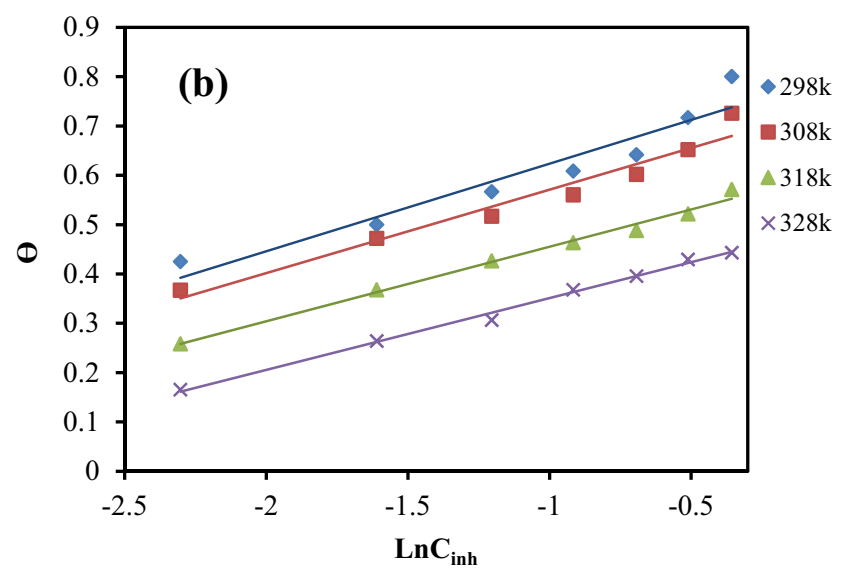

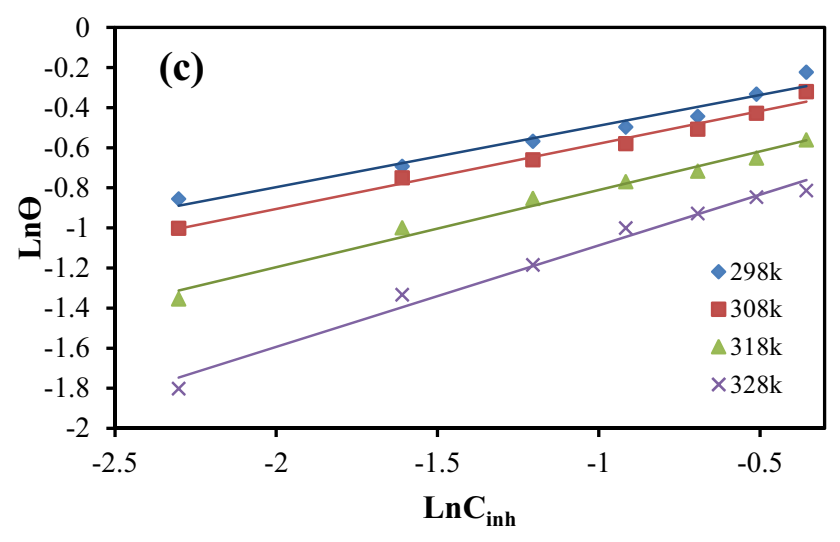

Fig. 6 Adsorption isotherms of $C B E$, a Langmuir isotherm, $\mathbf{b}$ Temkin isotherm, $\mathbf{c}$ Freundlich isotherm 


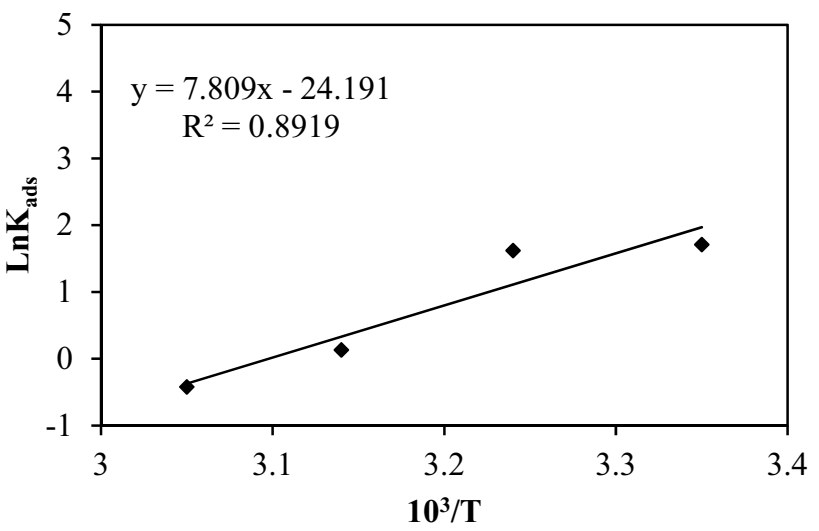

Fig. 7 Van't Hoff plot for CS in $1 \mathrm{M} \mathrm{HCl}$

those around $-40 \mathrm{~kJ} \cdot \mathrm{mol}^{-1}$ correspond to the formation of covalent bonds (chemisorption) [48, 49]. In our study,

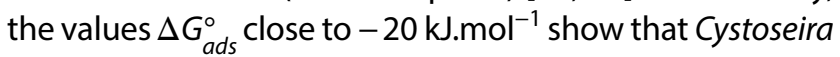
baccata extract adsorbed physically on the surface of the steel.

The enthalpy and entropy of adsorption $\left(\Delta H_{a d s}^{\circ}\right.$ and $\Delta S_{a d s}^{\circ}$ ) can be determined from the Van't Hoff equation expressed by [50]:

$\ln k_{a d s}=-\frac{\Delta H_{a d s}^{\circ}}{R T}+C$

The slopes of straight lines $\operatorname{lnk}_{\text {ads }}$ versus $1 / T$ are $\left(-\Delta H_{a d s}^{\circ} / R\right.$ and intercepts of $\left[\left(-\Delta S_{a d s}^{\circ} / R-\operatorname{Ln}\left(C_{\mathrm{H}_{2} \mathrm{O}}\right)\right]\right.$. The plot of the variations of Inkads versus $1 / T$ which gives straight lines (Fig. 7) with slopes of $\left(-\Delta H_{a d s}^{\circ} / R\right)$ and intercepts of $\left[\left(-\Delta S_{\text {ads }}^{\circ} / R\right)-\operatorname{Ln}\left(C_{\mathrm{H}_{2} \mathrm{O}}\right)\right]$.

The endothermic character of $\Delta H_{a d s}^{\circ}$ always binds to chemisorption, While the exothermic process of adsorption can be associated to physisorption or chemisorption. Depending on its value, physisorption close to $-40 \mathrm{~kJ}$. $\mathrm{mol}^{-1}$, otherwise close to $-100 \mathrm{~kJ}^{\mathrm{mol}}{ }^{-1}$ for chemisorption [51]. Value of $\Delta H_{\text {ads }}^{\circ}\left(-64.92 \mathrm{~kJ} \mathrm{~mol}^{-1}\right)$ indicates that physical adsorption is more favoured. The negative values $\Delta S_{\text {ads }}^{\circ}\left(-56.14 \mathrm{~J} \mathrm{~mol}^{-1}\right)$, it might be explained by the inhibitory molecules ordinarily adsorbed onto steel surface [52].

\subsection{Kinetic parameters of activation}

For a better understanding of the kinetic process of steel corrosion and the determination of the activation energy $\left(E_{a}\right)$ the following Arrhenius Eq. (13) was used [52]:

$\operatorname{Ln}(w)=A-\frac{E a}{R T}$

where $w$ is corrosion rate, $E_{a}$ is the apparent activation energy of the corrosion process, $R$ is the universal gas

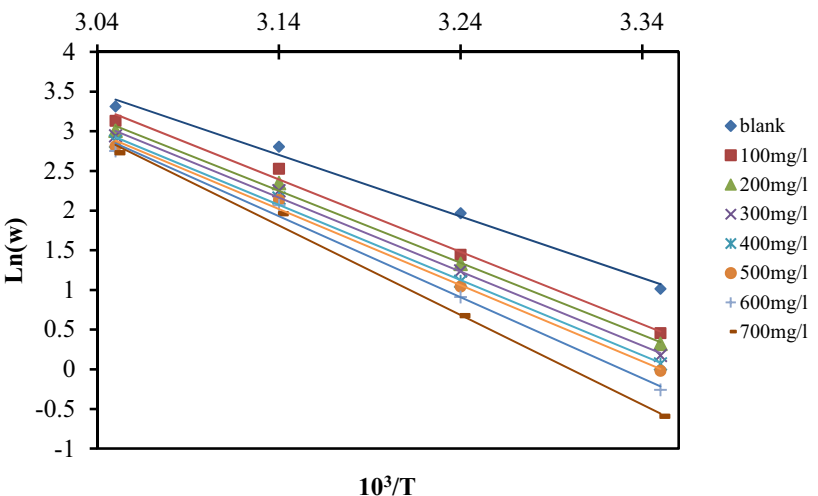

Fig. 8 Arrhenius plots for CS in $1 \mathrm{M} \mathrm{HCl}$, in the absence and presence of various concentrations of $C B E$

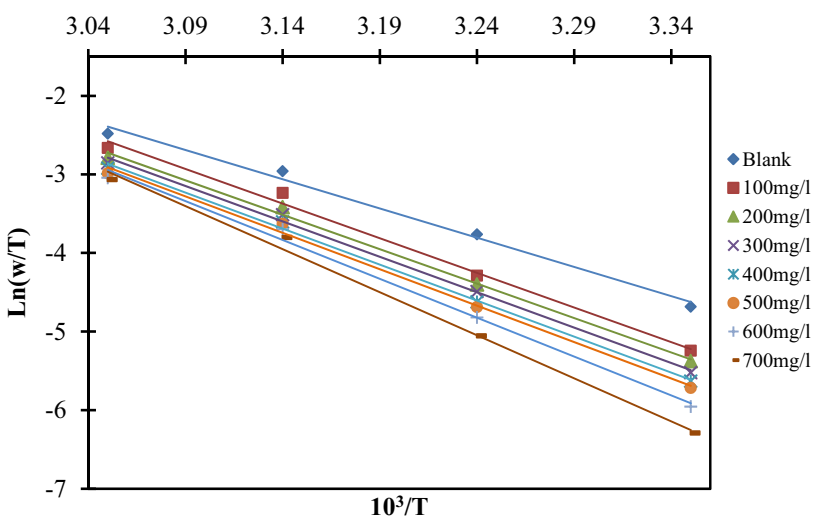

Fig. 9 Curve of the relationship between $L n(w / T)$ and $1 / T$ of steel for various concentrations of $C B E$ in $1 \mathrm{M} \mathrm{HCl}$

constant, $A$ is the Arrhenius pre-exponential factor and $T$ is the absolute temperature.

The Arrhenius diagrams (Fig. 8) of the logarithm of the corrosion rate obtained by measuring the weight loss to $10^{3} / \mathrm{T}$ for the blank and the different concentrations of the extract have a linear constriction, with a slope of $\left(-E_{d} / R\right)$.

The standard activation enthalpy $\left(\Delta H_{a}{ }^{\circ}\right)$ and standard activation entropy $\left(\Delta S_{a}{ }^{\circ}\right)$ of the corrosion process are calculated using the alternative formulation of the Arrhenius equation:

$\ln \left(\frac{w}{T}\right)=\left[\ln \left(\frac{R}{N_{a} h}\right)+\frac{\Delta S_{a}^{\circ}}{R}\right]-\frac{\Delta H_{a}^{\circ}}{R T}$

where his Plank's constant, $N_{a}$ is Avogadro's number, $\Delta S_{a}{ }^{\circ}$ and $\Delta H_{a}{ }^{\circ}$ are, respectively, the entropy and enthalpy of activation.

Figure 9 shows the curves of $\ln (w / T)$ versus the reciprocal of the temperature $\left(10^{3} / T\right)$, presented in the form of straight lines with an equal slope $\left(-\Delta H_{a} \% \mathrm{R}\right)$ and an 
Table 5 Activation parameters for $\mathrm{CS}$ in $1 \mathrm{M} \mathrm{HCl}$, with absence and presence of various $C B E$ concentrations

\begin{tabular}{lllll}
\hline $\begin{array}{l}\text { Concentration } \\
(\mathrm{mg} / \mathrm{l})\end{array}$ & $\begin{array}{l}\mathrm{E}_{\mathrm{a}} \\
(\mathrm{kJ} / \mathrm{mol})\end{array}$ & $\begin{array}{l}\Delta \mathrm{H}_{\mathrm{a}}^{\circ} \\
(\mathrm{kJ} / \mathrm{mol})\end{array}$ & $\begin{array}{l}\Delta \mathrm{S}_{\mathrm{a}}^{\circ} \\
(\mathrm{j} / \mathrm{mol})\end{array}$ & $\begin{array}{l}\mathrm{E}_{\mathrm{a}}-\Delta \mathrm{H}_{\mathrm{a}}{ }^{\circ} \\
(\mathrm{kJ} / \mathrm{mol})\end{array}$ \\
\hline Blank & 64.50 & 61.85 & 160.50 & 2.65 \\
100 & 75.92 & 73.27 & 193.77 & 2.65 \\
200 & 75.54 & 72.88 & 191.38 & 2.65 \\
300 & 77.55 & 74.90 & 196.99 & 2.65 \\
400 & 78.79 & 76.14 & 200.14 & 2.65 \\
500 & 79.74 & 77.08 & 202.66 & 2.65 \\
600 & 84.92 & 82.26 & 218.15 & 2.65 \\
700 & 93.75 & 91.10 & 244.93 & 2.65 \\
\hline
\end{tabular}

ordinate at the origin $\left(\operatorname{Ln} R / \mathrm{Nh}+\Delta \mathrm{S}_{a}{ }^{\circ} / R\right)$. All activation parameters $E_{a}, \Delta H_{a}^{\circ} \& \Delta S_{a}^{\circ}$ are grouped in Table 5. The $E_{a}$ values in the presence of the CBE are higher than those of the un-inhibited acidic solution. This increase in $E_{a}$ value may be interpreted as physisorption [53].Moreover, Belghiti et al. [54] explained that the increase in $\mathrm{E}_{\mathrm{a}}$ value can be attributed to an appreciable decrease in the adsorption of the inhibitor on the CS-surface with an increase in temperature. This means that an increase of temperature favored desorption over adsorption. Then the adsorption-desorption equilibrium tends towards the desorption of inhibitor molecules at higher temperatures. Due to the increased desorption of adsorbed molecules, the greater surface area of CS comes into contact with a corrosive medium, resulting in increased corrosion rates with increasing temperature. On the other hand, the thermodynamic parameter descriptors, $\Delta H_{a}^{\circ} \& \Delta S_{a}^{\circ}$, were calculated and depicted in Table 5. The positive signs of the enthalpies $\Delta H_{a}^{\circ}$ reflect the endothermic nature of the steel dissolution process. The activation entropy $\Delta S_{a}^{\circ}$ is positive in absence and presence of inhibitor this value increases positively with the extract concentration indicate that an increase of the disorder during the transformation of the reagents into activated complex [54]. The values of the difference $\left(\Delta H_{a}^{\circ}\right)$ are close to the mean value of the product RT $\left(2.63 \mathrm{~kJ} \mathrm{~mol}^{-1}\right)$, where $T$ is between $298 \mathrm{~K}$ and $328 \mathrm{~K}$, this is explained by the fact that the process of corrosion is a unimolecular reaction. Characterized by the following equation [55].

$E_{a}-\Delta H_{a}^{\circ}=R T$

\subsection{FTIR spectra analysis}

The Fourier Transform infrared spectra of $C B E$ and the scraped product from the steel surface have been presented in Fig. 10a, b, respectively. These spectra can
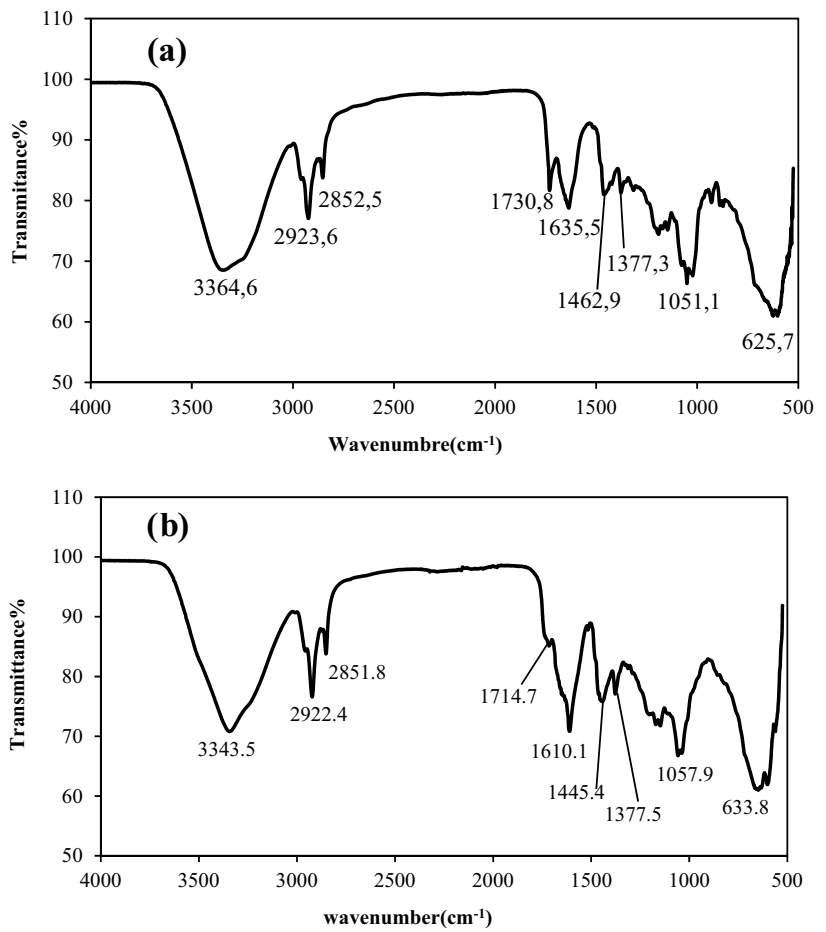

Fig. 10 FTIR spectra of $\mathbf{a} C B E$ and $\mathbf{b}$ the scrapped product from steel surface after immersion in $1 \mathrm{M} \mathrm{HCl}$ containing $700 \mathrm{mg} / \mathrm{l}$ of $C B E$

provide some information about the nature of the molecules present in the extract and also the possibility of the existence of interactions between them with the surface of the metal. Indeed, the Fig. 10a shows the presence of a band around $3364.6 \mathrm{~cm}^{-1}$, which is often attributed to the stretching vibration $(\mathrm{O}-\mathrm{H})$. The peaks at 2923.6 and $2852.5 \mathrm{~cm}^{-1}$ can be due to stretching vibration of aliphatic and aromatic $(\mathrm{C}-\mathrm{H})$ groups, respectively. The peak at $1730.8 \mathrm{~cm}^{-1}$ indicates the presence of the stretching modes of carbonyl groups $(\mathrm{C}=\mathrm{O})$. While the peak at $1635.5 \mathrm{~cm}^{-1}$ corresponds to the stretching vibration of the aromatic ring $(C=C)$. The peak at $1462.6 \mathrm{~cm}^{-1}$ can be assigned to the stretching vibration $(\mathrm{C}-\mathrm{C})$, and the peak at $1051 \mathrm{~cm}^{-1}$ indicates the presence of $\mathrm{C}-\mathrm{O}$ stretching $[56,57]$. Furthermore, the Fig. $10 \mathrm{~b}$ shows a shift in the absorption wavelength after immersion in $\mathrm{HCl} 1 \mathrm{M}$. This wavelength shift indicates that the $C B E$ is by adsorption by forming interaction with the steel surface $[58,59]$.

\subsection{Adsorption mechanism}

The adsorption mechanism in the case of natural extracts is generally difficult to interpret. This difficulty is mainly due to the complexity of the chemical composition of the extracts. Generally, the organic molecules can adsorb on the surface of the metal as neutral molecules or as cations through electrostatic interactions [60]. The chemical composition of 
Cystoseira baccata mentioned in the bibliography reveals that it is an alga rich in meroditerpenoids compounds that contain carbonyl functions $(\mathrm{C}=\mathrm{O})$, benzenyl rings and hydroxyl groups $(\mathrm{OH})[19,61]$, and phlorotannins, which are polyphenol compounds resulting from the polymerization of phloroglucinol and which contain phenyl rings et hydroxyl groups $(\mathrm{OH})[62,63]$. The $C B E$ inhibitor molecules possess $(\mathrm{d} \pi-\mathrm{d} \pi$ )-electrons (cyclic rings) that can potentially act as proton and/or hydrogen-bond acceptor sites and also contain electronegative elements (-O-) that have isolated and/or delocalized lone pairs $(\sigma)$ of electrons interact with Fe 3d-electrons in CS surface [32,60]. It is can be adsorbed onto the CS surface in several ways. In the case of physical adsorption, the charge on the surface of the metal may promote or hinder the adsorption of a species. A negative surface charge will favour the adsorption of cations, whereas anion adsorption is supported by a positive surface charge [60]. However, in acid solutions, organic molecules can easily be protonated, from which they are presented in the form of cations [33]. The metal charge can be determined from the difference between the corrosion potential $E_{c o r r}$ and the zero charge potential $E_{0}$. In our study, the surface of the steel positively charged $\left(E_{c o r r}-E_{0}>0\right)$ [28]. The $\mathrm{Cl}^{-}$anions could be specifically adsorbed to the surface of the carbon steel; they create excess negative charge toward the solution and favour more adsorption of the cations on the negatively charged metal surface through electrostatic interactions $[28,33]$.

\section{Conclusion}

- The three methods used, gravimetry, polarization curve, electrochemical impedance spectroscopy, show that Cystosira baccata extract acts as a suitable corrosion inhibitor, and the inhibitory efficiency (IE\%) increases with concentration.

- The electrochemical studies indicate that extract acts as a mixed type inhibitor. The charge transfer resistance increases; on the other hand, the double-layer capacity decreases with increasing the concentration inhibitor.

- The study of the effect of temperature and the determination of the thermodynamic parameters of adsorption confirms that the $C B E$ adsorbs physically on the metal surface and that the adsorption obeys the Langmuir isotherm.

- The FTIR spectra analysis confirms the adsorption of $C B E$ extract molecules on the CSsurface.

- The fractionation operations are being carried out to determine the molecule (s) responsible for the corrosion inhibiting effect.

\section{Compliance with ethical standards}

Conflict of interest On behalf of all authors, I declare that there is no conflict of interest.

\section{References}

1. Samiee R, Ramezanzadeh B, Alibakhshi E (2018) Corrosion inhibition performance and healing ability of a hybrid silane coating in the presence of praseodymium (III) cations. J Electrochem Soc 165:777-786. https://doi.org/10.1149/2.0841811jes

2. McCafferty E (2010) Introduction to corrosion science. Springer, New York, pp 357-402

3. Goyal M, Kumar S, Bahadur l et al (2018) Organic corrosion inhibitors for industrial cleaning of ferrous and non-ferrous metals in acidic solutions: a review. J Mol Liq 256:565-573. https://doi. org/10.1016/j.molliq.2018.02.045

4. Athar M, Ali H, Quraishi M (2002) Corrosion inhibition of carbon steel in hydrochloric acid by organic compounds containing heteroatoms. Br Corros J 37:155-158. https://doi.org/10.1016/j. electacta.2008.03.021

5. Sastri VS (2011) Green corrosion inhibitors: theory and practice. Wiley, London, pp 167-211. https://doi.org/10.1002/97811 18015438

6. Palou RM, Olivares-Xomelt O, Likhanova NV (2014) Environmentally friendly corrosion inhibitors. In: Developments in corrosion protection. InTech, pp 431-465. https://doi.org/10.5772/57252

7. El Attari H, Chefira K, Rchid H et al (2019) Corrosion inhibition study of the origanum elongatum extract: sulfuric acid. Res J Pharm Biol Chem Sci 10:1491-1507

8. Topal E, Gece G (2018) A theoretical study on chemically elegant proton pump inhibitors in search of novel green corrosion inhibitors. Prot Met Phys Chem Surf 53(6):1173-1180. https:// doi.org/10.1134/S2070205118010288

9. Ebuka D, Stephen A, Abechi E (2019) Corrosion inhibition studies of mild steel using Acalypha chamaedrifolia leaves extract in hydrochloric acid medium. SN Appl Sci 1:1089. https://doi. org/10.1007/s42452-019-1138-4

10. Khadraoui A, Khelifa A (2014) Synergistic effect of potassium iodide in controlling the corrosion of steel in acid medium by Mentha pulegium extract. Res Chem Intermed 41:7973-7980. https://doi.org/10.1007/s11164-014-1870-8

11. Rajan JP, Shrivastava R, Mishra RK (2018) Corrosion inhibition effect of clerodendron colebrookianum Walp leaves (Phuinam) extract on the acid corrosion of mild steel. Prot Met Phys Chem Surf. https://doi.org/10.1134/S2070205118010264

12. Benghalia MA, Fares $C$, Khadraoui A et al (2018) Performance evaluation of a natural and synthetic compound as corrosion inhibitors of API 5 I X52 steel in hydrochloric acid media. Moroccan J Chem 6:51-61

13. Dehghani A, Bahlakeh G, Ramezanzadeh B, Ramezanzadeh M (2019) Potential of Borage flower aqueous extract as an environmentally sustainable corrosion inhibitor for acid corrosion of mild steel: electrochemical and theoretical studies. J Mol Liq 277:895-911. https://doi.org/10.1016/j.molliq.2019.01.008

14. Verma DK, Khan F (2016) Green approach to corrosion inhibition of mild steel in hydrochloric acid medium using extract of spirogyra algae. Green Chem Lett Rev 9(1):52-60

15. Nadi I, Belattmania Z, Sabour B et al (2019) Sargassum muticum extract based on alginate biopolymer as a new efficient biological corrosion inhibitor for carbon steel in hydrochloric acid pickling environment: gravimetric, electrochemical and 
surface studies. Int J Biol Macromol 141:137-149. https://doi. org/10.1016/j.jibiomac.2019.08.253

16. Benabbouha T, Siniti M, El Attari $\mathrm{H}$ et al (2018) Red algae Halopitys Incurvus extract as a green corrosion inhibitor of carbon steel in hydrochloric acid. J Bio Tribo-Corrosion 4:2-9. https:// doi.org/10.1007/s40735-018-0161-0

17. Manimegalai S, Manjula P (2015) Thermodynamic and adsorption studies for corrosion inhibition of mild steel in aqueous media by Sargasam swartzii (Brown algae). J Mater Environ Sci 6:1629-1637

18. Spavieri J, Allmendinger A, Kaiser M et al (2010) Antimycobacterial, antiprotozoal and cytotoxic potential of twenty-one brown algae (phaeophyceae) from British and Irish waters. Phytother Res 24:1724-1729. https://doi.org/10.1002/ptr.3208

19. Mokrini R, Ben Mesaoud M, Daoudi M et al (2008) Meroditerpenoids and derivatives from the brown alga Cystoseira baccata and their antifouling properties. J Nat Prod 71:1806-1811. https ://doi.org/10.1021/np8004216

20. Gouveia V, Seca AML, Barreto MC, Pinto DCGA (2013) Di- and sesquiterpenoids from Cystoseira genus: structure, intra-molecular transformations and biological activity. Mini Rev Med Chem 13:1150-1159. https://doi.org/10.2174/1389557511313080003

21. Bruno de Sousa C, Gangadhar KN, Morais TR et al (2017) Antileishmanial activity of meroditerpenoids from the macroalgae Cystoseira baccata. Exp Parasitol 174:1-9. https://doi. org/10.1016/j.exppara.2017.01.002

22. Fernandes CM, Fagundes SF, Escarpini $N$ et al (2019) Ircinia strobilina crude extract as corrosion inhibitor for mild steel in acid medium. Electrochim Acta. https://doi.org/10.1016/j.elect acta.2019.04.148

23. Khadraoui A, Khelifa A, Boutoumi H et al (2016) The oil from mentha rotundifolia as green inhibitor of carbon steel corrosion in hydrochloric acid. Chem Eng Commun 203:270-277. https:// doi.org/10.1080/00986445.2014.993469

24. Ferreira ES, Giacomelli C, Giacomelli FC, Spinelli A (2004) Evaluation of the inhibitor effect of L-ascorbic acid on the corrosion of mild steel. Mater Chem Phys 83:129-134. https://doi. org/10.1016/j.matchemphys.2003.09.020

25. El-lateef HMA (2014) Experimental and computational investigation on the corrosion inhibition characteristics of mild steel by some novel synthesized imines in hydrochloric acid solutions. Corros Sci. https://doi.org/10.1016/j.corsci.2014.11.040

26. Mobin M, Aslam R, Aslam J (2017) Nontoxic biodegradable cationic gemini surfactants as novel corrosion inhibitor for mild steel in hydrochloric acid medium and synergistic effect of sodium salicylate: experimental and theoretical approach. Mater Chem Phys 191:151-167. https://doi.org/10.1016/j.match emphys.2017.01.037

27. Roy P, Pal A, Sukul D (2014) Origin of the synergistic effect between polysaccharide and thiourea towards adsorption and corrosion inhibition for mild steel in sulphuric acid. RSC Adv 4:10607. https://doi.org/10.1039/c3ra46549g

28. Bensouda Z, Hassan E, Assiri E et al (2019) Extraction, characterization and anticorrosion potential of an essential oil from orange zest as eco-friendly inhibitor for mild steel in acidic solution. J Bio- and Tribo-Corros 5:84. https://doi.org/10.1007/s4073 5-019-0276-y

29. Shah AM, Rahim AA, Mohamad Ibrahim MN, Hussin MH (2017) Depolymerized oil palm frond (OPF) lignin products as corrosion inhibitors for mild steel in $1 \mathrm{M} \mathrm{HCl}$. Int J Electrochem Sci 12:9017-9039. https://doi.org/10.20964/2017.10.66

30. Obot IB, Madhankumar A (2016) Synergistic effect of iodide ion addition on the inhibition of mild steel corrosion in $1 \mathrm{M} \mathrm{HCl}$ by 3-amino-2-methylbenzylalcohol. Mater Chem Phys 177:266275. https://doi.org/10.1016/j.matchemphys.2016.04.027
31. Khaled KF, Hackerman N (2004) Ortho -substituted anilines to inhibit copper corrosion in aerated $0.5 \mathrm{M}$ hydrochloric acid. Electrochim Acta 49:485-495. https://doi.org/10.1016/j.elect acta.2003.09.005

32. El-Hajjaji F, Messali M, Aljuhani A et al (2018) Pyridaziniumbased ionic liquids as novel and green corrosion inhibitors of carbon steel in acid medium: electrochemical and molecular dynamics simulation studies. J Mol Liq 249:997-1008. https:// doi.org/10.1016/j.molliq.2017.11.111

33. Soltani N, Khayatkashani M (2015) Gundelia tournefortii as a green corrosion inhibitor for mild steel in $\mathrm{HCl}$ and $\mathrm{H}_{2} \mathrm{SO}_{4}$ solutions. Int J Electrochem Sci 10:46-62

34. Belghiti ME, Mihit M, Mahsoune A et al (2019) Studies of Inhibition effect "E\&Z" configurations of hydrazine derivatives on mild steel surface in phosphoiric acid. J Mater Res Technol 8:6336-6353. https://doi.org/10.1016/j.jmrt.2019.09.051

35. Popova A, Raicheva S, Sokolova E, Christov M (1996) Frequency dispersion of the interfacial impedance at mild steel corrosion in acid media in the presence of benzimidazole derivatives. Langmuir 12:2083-2089

36. Ouici H, Tourabi M, Benali O et al (2017) Adsorption and corrosion inhibition properties of 5-amino 1,3,4-thiadiazole-2-thiol on the mild steel in hydrochloric acid medium: thermodynamic, surface and electrochemical studies. J Electroanal Chem 803:125-134. https://doi.org/10.1016/j.jelec hem.2017.09.018

37. Verma C, Quraishi MA (2017) 2-Amino-4-(2,4-dihydroxyphenyl) quinoline-3 carbonitrile as sustainable corrosion inhibitor for SAE 1006 steel in $1 \mathrm{M} \mathrm{HCl}$ : electrochemical and surface investigation. J Assoc Arab Univ Basic Appl Sci 23:29-36. https ://doi.org/10.1016/j.jaubas.2016.03.002

38. Hegazy MA, Aiad I (2015) 1-Dodecyl-4-(((3-morpholinopropyl) imino)methyl)pyridin-1-ium bromide as a novel corrosion inhibitor for carbon steel during phosphoric acid production. J Ind Eng Chem 31:91-99. https://doi.org/10.1016/j. jiec.2015.06.012

39. Papavinasam S (2000) Corrosion inhibitors. In: Uhlig's corrosion handbook, 2nd edn. Wiley, New York, pp 1089-1105

40. Nahle A, Ideisan I, Abou-Abdoun I, Abdel-Rahman I (2012) Inhibition of mild steel corrosion by 3-benzoylmethyl benzimidazolium hexafluoroantimonate in acidic solution. Int J Corros. https ://doi.org/10.1155/2012/246013

41. Langmuir I (1917) The constitution and fundamental properties of solids and liquids. II. Liquids. J Am Chem Soc 39:1848-1906. https://doi.org/10.1021/ja02254a006

42. Temkin MJ, Pyzhev V (1940) Recent modifications to Langmuir isotherms. Acta Physiochim URSS 12:217-222

43. Basar CA (2006) Applicability of the various adsorption models of three dyes adsorption onto activated carbon prepared waste apricot. J Hazard Mater 135:232-241. https://doi.org/10.1016/j. jhazmat.2005.11.055

44. Dohare P, Ansari KR, Quraishi MA, Obot IB (2017) Pyranpyrazole derivatives as novel corrosion inhibitors for mild steel useful for industrial pickling process: experimental and quantum chemical study. J Ind Eng Chem 52:197-210. https://doi.org/10.1016/j. jiec.2017.03.044

45. Dada A, Olalekan A, Olatunya A, Dada O (2012) Langmuir, Freundlich, Temkin and Dubinin-Radushkevich isotherms studies of equilibrium sorption of $\mathrm{Zn} 2+$ unto phosphoric acid modified rice husk. J Appl Chem 3:38-45

46. Beniken M, Driouch M, Sfaira M et al (2018) Kinetic-thermodynamic properties of a polyacrylamide on corrosion inhibition for C-steel in 1.0 M HCl Medium: part 2. J Bio-Tribo-Corros 4:34. https://doi.org/10.1007/s40735-018-0152-1

47. Saratha R, Meenakshi R (2010) Corrosion inhibitor: a plant extract. Der Pharma Chem 2:287-294 
48. Nesakumar T, Immanuel J, Atchudan R et al (2018) Corrosion inhibition performance of spermidine on mild steel in acid media. J Mol Liq 264:483-489. https://doi.org/10.1016/j.molli q.2018.05.087

49. Cherappanath RJ, John VD (2018) Synthesis, characterization, anti-corrosive/anti-tumor applications of a new type arylazo compound 1, 7-bis (2-hydroxy phenyl)-4-(phenyl hydrazono)hepta-1, 6-diene-3, 5-dione. J Bio-Tribo-Corros 4(4):p66. https ://doi.org/10.1007/s40735-018-0183-7

50. Zarrouk A, Hammouti B, Dafali A, Bentiss F (2013) Inhibitive properties and adsorption of purpald as a corrosion inhibitor for copper in nitric acid medium. Ind Eng Chem Res 52:2560-2568

51. Douadi T, Hamani H, Daoud D et al (2017) Effect of temperature and hydrodynamic conditions on corrosion inhibition of an azomethine compounds for mild steel in $1 \mathrm{M} \mathrm{HCl}$ solution. J Taiwan Inst Chem Eng 71:388-404. https://doi.org/10.1016/j. jtice.2016.11

52. Masroor S, Singh MMAK, Shoeb RAKRM (2020) Aspartic didodecyl ester hydrochloride acid and its ZnO-NPs derivative, as ingenious green corrosion defiance for carbon steel through theoretical and experimental access. SN Appl Sci 2:144. https:// doi.org/10.1007/s42452-019-1515-z

53. Hachama K, Khadraoui A, Zouikri M et al (2015) Synthesis, characterization and study of methyl 3-(2-oxo-2H-1,4-benzoxazin3-yl) propanoate as new corrosion inhibitor for carbon steel in $1 \mathrm{M} \mathrm{H}_{2} \mathrm{SO}_{4}$ solution. Res Chem Intermed 42:987-996. https://doi. org/10.1007/s11164-015-2068-4

54. Belghiti ME, Bouazama S, Echihi S et al (2020) Understanding the adsorption of newly Benzylidene- aniline derivatives as a corrosion inhibitor for carbon steel in hydrochloric acid solution: experimental, DFT and molecular dynamic simulation studies. Arab J Chem 13:1499-1519. https://doi.org/10.1016/j.arabj c.2017.12.003

55. Singh AK, Mohapatra S, Pani B (2016) Corrosion inhibition effect of Aloe Vera gel: gravimetric and electrochemical study. J Ind Eng Chem 33:288-297. https://doi.org/10.1016/j. jiec.2015.10.014

56. Satapathy AK, Gunasekaran G, Sahoo SC et al (2009) Corrosion inhibition by Justicia gendarussa plant extract in hydrochloric acid solution. Corros Sci 51:2848-2856. https://doi. org/10.1016/j.corsci.2009.08.016

57. Saxena A, Prasad D, Haldhar R et al (2018) Use of Sida cordifolia extract as green inhibitor for mild steel in $0.5 \mathrm{M} \mathrm{H}_{2} \mathrm{SO}_{4}$. J Environ Chem Eng 6:694-700. https://doi.org/10.1016/j.jece.2017.12.064

58. Khadom AA, Abd AN, Arif N (2018) Xanthium strumarium leaves extracts as a friendly corrosion inhibitor of low carbon steel in hydrochloric acid: kinetics and mathematical studies. S Afr J Chem Eng 25:13-21. https://doi.org/10.1016/j.sajce.2017.11.002

59. Kavitha S, Kathiravan N, Jyothi A et al (2019) Adsorption and inhibitive properties of methanol extract of Leucas aspera leaves for the corrosion of mild steel in $\mathrm{HCl}$ medium. J Bio-Tribo-Corros 5:51. https://doi.org/10.1007/s40735-019-0244-6

60. Bentiss F, Traisnel M, Lagrenee M (2000) The substituted 1, 3, 4-oxadiazoles: a new class of corrosion inhibitors of mild steel in acidic media. Corros Sci 42:127-146

61. Valls R, Piovetti L, Banaigs B, Praud A (1993) Secondary metabolites from morocco of the genus Cystoseira. Phytochemistry 32:961-966

62. Glombitza KW, Wiedenfeld G, Eckhardt G (1978) Niedermolekulare Phlorotannine aus Cystoseira baccata. Arch Pharm 311:393-399

63. Glombitz KW, Rosener HU, Muller D (1975) Bifuhalol Und Diphlorethol Aus Cystoseira Tamariscifolia. Phytochemistry 14:1115-1116

Publisher's Note Springer Nature remains neutral with regard to jurisdictional claims in published maps and institutional affiliations. 